\title{
Motion - Patients with primary sclerosing cholangitis should undergo early liver transplantation: Arguments against the motion
}

\author{
Jeffrey S Crippin MD
}

JS Crippin. Motion - Patients with primary sclerosing cholangitis should undergo early liver transplantation: Arguments against the motion. Can J Gastroenterol 2002; 16(10):700-702.

Liver transplantation is an accepted form of treatment for patients with primary sclerosing cholangitis (PSC) and can provide long term survival. Cholangiocarcinoma occurs in $10 \%$ to $20 \%$ of patients with PSC, is difficult to diagnose and has a poor prognosis. It has been proposed that liver transplantation be undertaken early in the course of the PSC, before cancer develops. Such a proposal would have significant implications for the method of assigning priority to patients awaiting liver transplantation. Other patients on the waiting list would experience further delays, while there is no proven benefit for PSC patients. Few patients with this disease are removed from the waiting list because they developed cancer. If one were to state that PSC patients warrant special consideration because of the hypothetical risk of cholangiocarcinoma, the same argument could be applied to patients with hepatitis C and other causes of cirrhosis, who are at increased risk of hepatocellular carcinoma. The transplant allocation system is applied in an equitable fashion to patients with a large variety of liver diseases. Alteration of this system to benefit a small number of patients with PSC would violate the principles on which it was created, and cannot be justified.

Key Words: Liver transplantation; Primary sclerosing cholangitis
Proposition - Les patients atteints de cholangite sclérosante primitive devraient subir une transplantation précoce du foie : arguments défavorables

RÉSUMÉ : La transplantation du foie est une forme de traitement acceptée pour les patients atteints de cholangite sclérosante primitive (CSP) et elle peut prolonger la survie. Le cholangiocarcinome se rencontre chez 10 à $20 \%$ des patients atteints de CSP, il est difficile à diagnostiquer et le pronostic est sombre. Alors, certains proposent de pratiquer une transplantation du foie au stade précoce de la CSP, avant même l'apparition du cancer. Ce genre de proposition se répercuterait très fortement sur la façon d'établir l'ordre de priorité chez les patients dans l'attente d'une transplantation hépatique. Des patients déjà inscrits sur la liste verraient leur opération reportée encore davantage, et rien ne prouve que le traitement est salutaire chez les patients atteints de CSP. Peu de ces derniers sont rayés de la liste d'attente en raison de l'apparition d'un cancer. L'argument voulant qu'il faille porter une attention particulière aux patients souffrant de CSP à cause d'un risque hypothétique de cholangiocarcinome pourrait s'appliquer également aux patients atteints d'hépatiteC ou d'autres causes de cirrhose qui connaissent des risques accrus de carcinome hépatocellulaire. Le système d'attribution des organes est appliqué de façon équitable parmi les patients souffrant de différentes maladies du foie. Le modifier aux seules fins de favoriser un petit nombre de patients atteints de CSP violerait les principes mêmes du système et ne se justifie nullement.

This article was originally presented at a symposium entitled, "Controversies in Gastroenterology", sponsored by Axcam Pharma, Toronto, Ontario, April 8 to 10, 2002

Washington University School of Medicine, 660 South Euclid Avenue, Campus Box 8124, St Louis, Missouri 63110, USA

Correspondence: Dr Jeffrey S Crippin, Washington University School of Medicine, 660 South Euclid Avenue, Campus Box 8124,

St Louis, Missouri 63110, USA. Telephone 314-454-5160, fax 314-454-5108, e-mail jcrippin@im.wustl.edu 
$\mathrm{L}_{\mathrm{r}}^{\mathrm{i}}$ iver transplantation is a well-accepted treatment for patients with primary sclerosing cholangitis (PSC). It is clearly beneficial for patients who manifest end stage liver disease and hepatic synthetic dysfunction, and results in excellent short and long term survival rates. Most centres report one-year survival rates of $90 \%$ to $94 \%$ and five-year survival rates of $82 \%$ to $84 \%(1-3)$. One study showed that $70 \%$ of patients survived for at least ten years (3). Transplantation is also helpful for patients without liver failure who experience recurrent episodes of bacterial cholangitis and sepsis.

Unfortunately, PSC patients are at increased risk for the development of cholangiocarcinoma $(4,5)$. This tumour can arise at any location in the biliary tree and is difficult to distinguish from the fibrotic biliary strictures that occur with the primary disease. Screening for the presence of cholangiocarcinoma with serologic and imaging studies yields many false positive and negative results $(6,7)$. Thus, the tumour is often advanced at the time of diagnosis. Survival rates for patients with cholangiocarcinoma are poor $(8)$, even with liver transplantation $(2,9,10)$, and most centres regard it as an absolute contraindication for this procedure. Preliminary results from a small single centre study suggested that chemotherapy and radiation therapy may improve survival in selected patients (11).

The poor prognosis of cholangiocarcinoma, which occurs in $10 \%$ to $20 \%$ of PSC patients, has led to attempts to improve the diagnostic and therapeutic modalities. Screening techniques, however, have done little to improve the outcome in these patients. One approach is to undertake liver transplantation early in the course of the disease to avert cholangiocarcinoma. Although this may seem to offer a simple solution to the problem, there are a number of reasons why this strategy is not feasible.

\section{LIMITED RESOURCES}

A major dilemma facing liver transplant centres worldwide is the inadequate number of donor organs. In the United States alone, more than 17,000 patients are on the transplant waiting list, and the number of liver transplantations that are performed has been relatively constant at $5000 /$ year for the past several years. Despite intensive efforts by the transplant community, the number of available cadaveric organs has remained static. This has occurred in the face of a steadily growing waiting list.

In the United States, $8 \%$ to $10 \%$ of patients on the liver transplant waiting list die before an appropriate donor organ is available. Death is usually due to a complication of liver failure. Therefore, any decision to perform a transplant on certain patients earlier would further delay the procedure for other patients on the waiting list. It is likely that longer waiting times would result in additional complications and deaths among these patients.

\section{LOGISTICAL CONCERNS}

A strategy for performing early transplantation in PSC patients would be difficult, if not impossible, to enact. The current waiting list is based on a 'point' system. Priority is given to patients according to accrued waiting time and the severity of liver disease. Exceptions to the rules do occur, and are usually based on the presence of hepatocellular carcinoma or other complications that could potentially shorten the patient's life span without transplantation. For example, patients with polycystic liver disease often have nearly normal hepatic synthetic function at the time of transplantation, but are placed at a similar priority level as patients with decompensated cirrhosis (Child-Turcotte-Pugh class C) because they suffer from such massive abdominal distension that they have difficulty maintaining an adequate nutritional intake.

One could similarly give special consideration to patients with PSC, such that they could be advanced to a higher priority level due to the risk of cholangiocarcinoma. No study, however, has proven that this is an effective way to avert this complication. Although some studies have suggested that patients with severely decompensated PSC are at a greater risk of cholangiocarcinoma (12), it has not been shown that fewer patients would develop malignancy if transplantation were performed earlier.

How often is a listed patient with PSC removed from the waiting list due to the development of cholangiocarcinoma? I can recall only a single case. Likewise, the presence of 'incidental' cholangiocarcinoma in the explanted liver is a relatively uncommon finding, occurring in $1.5 \%$ to $8 \%$ of cases in three large series $(2,3,9)$. These data indicate that relatively few PSC patients would benefit from a policy of early transplantation.

Finally, why should PSC patients gain this advantage when all patients with cirrhosis are at risk of developing hepatocellular carcinoma while they are on the waiting list? For example, $5 \%$ to $10 \%$ of patients with cirrhosis due to hepatitis C develop hepatocellular carcinoma, and, thus, may qualify for special consideration. Shouldn't this group of patients have a similar access to donor organs as have those with PSC? After all, there is good evidence that larger tumours are associated with decreased survival rates.

The strength of the United Network of Organ Sharing allocation system is its applicability to a broad range of patients with various complications of acute and chronic liver disease. If the system were to be changed to one involving the 'micromanagement' of specific cases, it would be impossible to operate efficiently. No one involved in the field of liver transplantation has ever claimed that the system is perfect. Nevertheless, trying to prioritize a large number of patients (400 to 500/year) based on special 'prophylactic' indications is not in keeping with the spirit in which the waiting list was constructed.

Thus, granting a transplant to patients with PSC earlier than the current allocation system allows is inappropriate. There appears to be little question that some patients would benefit from such a policy but, until there is evidence that at least a majority of patients would realize an improved outcome, it is impossible to support this proposal. 


\section{REFERENCES}

1. Narumi S, Roberts JP, Emond JC, Lake J, Ascher NL. Liver transplantation for sclerosing cholangitis. Hepatology 1995;22:451-7.

2. Goss JA, Shackleton CR, Farmer DG, et al. Orthotopic liver transplantation for primary sclerosing cholangitis. A 12-year single center experience. Ann Surg 1997;225:472-81.

3. Graziadei IW, Wiesner RH, Marotta PJ, et al. Long-term results of patients undergoing liver transplantation for primary sclerosing cholangitis. Hepatology 1999;30:1121-7.

4. Rosen CB, Nagorney DM, Wiesner RH, Coffey RJ Jr, LaRusso NF. Cholangiocarcinoma complicating primary sclerosing cholangitis. Ann Surg 1991;213:21-5.

5. Chalasani N, Baluyut A, Ismail A, et al. Cholangiocarcinoma in patients with primary sclerosing cholangitis: A multicenter casecontrol study. Hepatology 2000;31:7-11.

6. Ramage JK, Donaghy A, Farrant JM, Iorns R, Williams R. Serum tumor markers for the diagnosis of cholangiocarcinoma in primary sclerosing cholangitis. Gastroenterology 1995;108:865-9.
7. Nichols JC, Gores GJ, LaRusso NF, Wiesner RH, Nagorney DM, Ritts RE Jr. Diagnostic role of serum CA 19-9 for cholangiocarcinoma in patients with primary sclerosing cholangitis. Mayo Clin Proc 1993;68:874-9.

8. Ahrendt SA, Pitt HA, Nakeeb A, et al. Diagnosis and management of cholangiocarcinoma in primary sclerosing cholangitis. J Gastrointest Surg 1999;3:357-67.

9. Abu-Elmagd KM, Malinchoc M, Dickson ER, et al. Efficacy of hepatic transplantation in patients with primary sclerosing cholangitis. Surg Gynecol Obstet 1993;177:335-44.

10. Goldstein RM, Stone M, Tillery GW, et al. Is liver transplantation indicated for cholangiocarcinoma? Am J Surg 1993;166:768-71.

11. De Vreede I, Steers JL, Burch PA, et al. Prolonged disease-free survival after orthotopic liver transplantation plus adjuvant chemoirradiation for cholangiocarcinoma. Liver Transpl 2000;6:309-16.

12. Nashan B, Schlitt HJ, Tusch G, et al. Biliary malignancies in primary sclerosing cholangitis: timing for liver transplantation. Hepatology 1996;23:1105-11. 


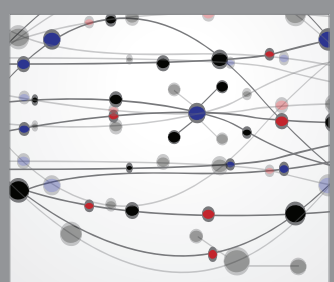

The Scientific World Journal
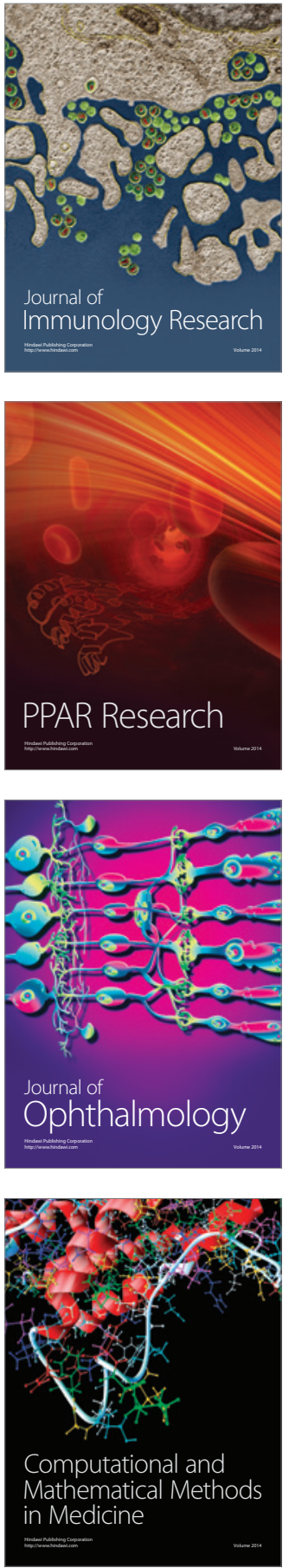

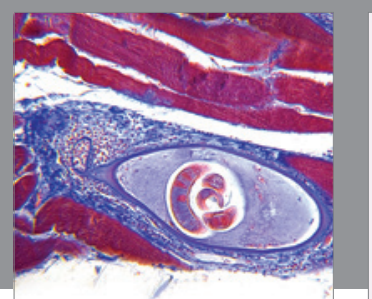

Gastroenterology Research and Practice

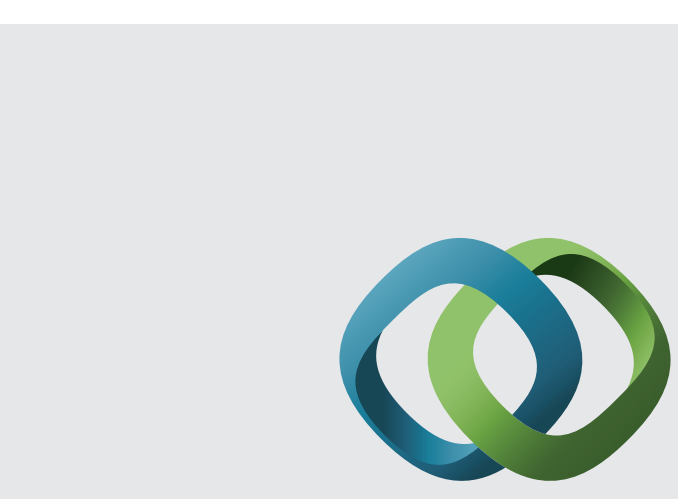

\section{Hindawi}

Submit your manuscripts at

http://www.hindawi.com
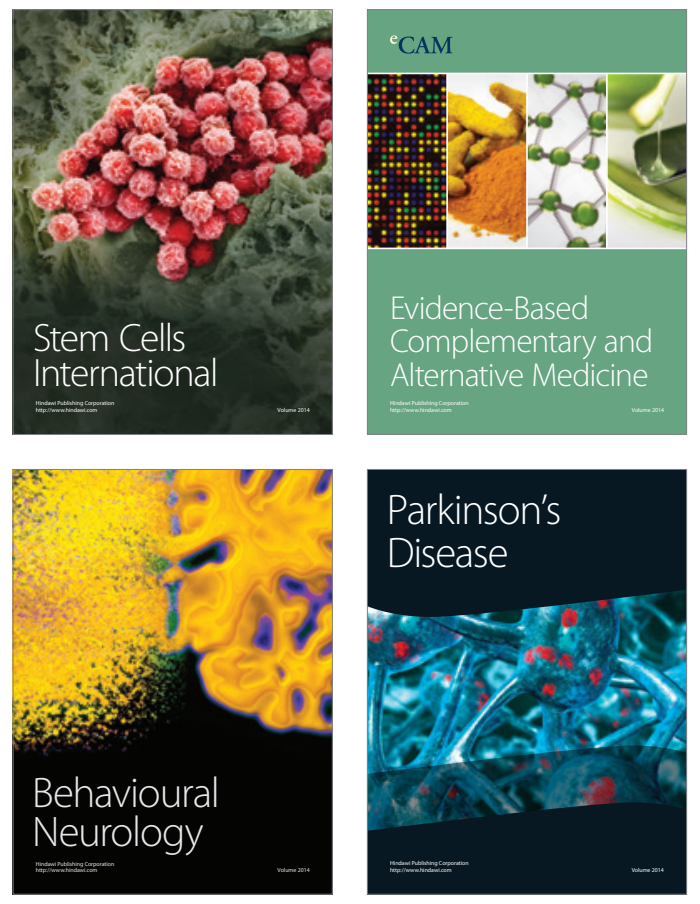
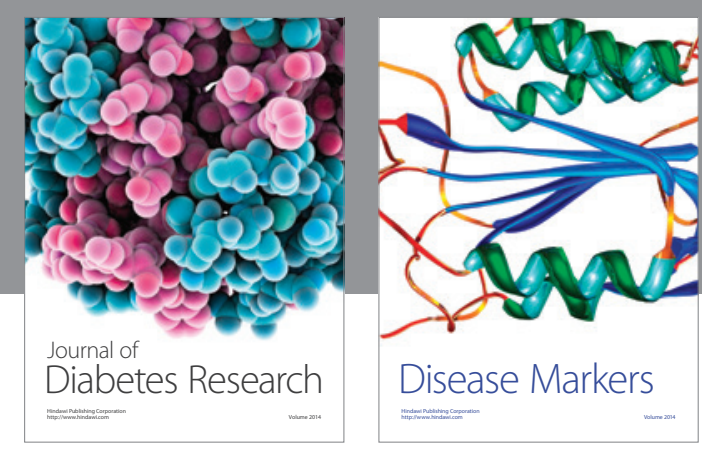

Disease Markers
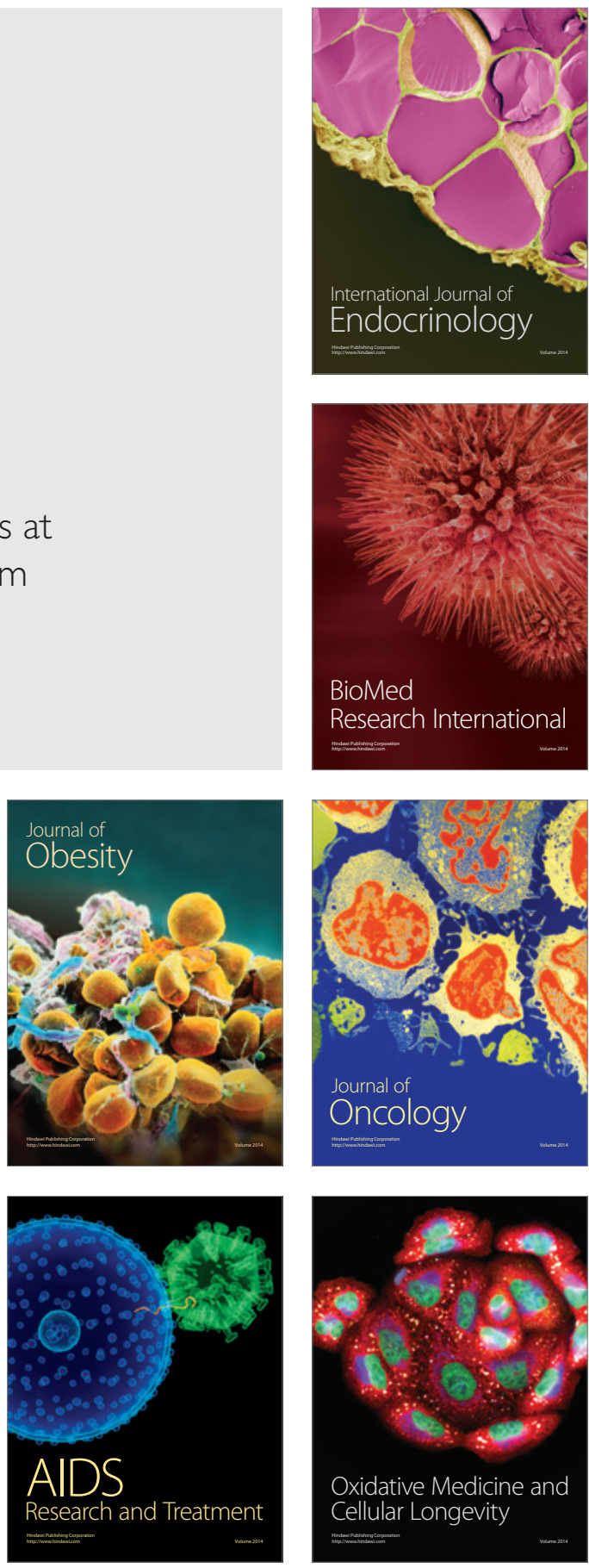